\title{
CYP2C19 Genetic Polymorphism and Pharmacodynamics of Prasugrel Maintenance Dose in Patients Undergoing Percutaneous Coronary Intervention
}

\author{
George Kassimis $^{\mathrm{a}, \mathrm{b}}$ Dimitrios Alexopoulos ${ }^{\mathrm{c}}$ \\ a Department of Cardiology, Cheltenham General Hospital, Gloucestershire Hospitals NHS, Foundation Trust,

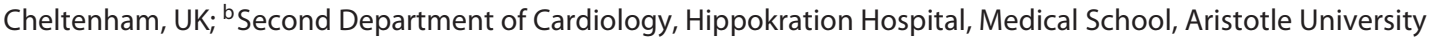 \\ of Thessaloniki, Thessaloniki, Greece; ' Second Department of Cardiology, Attikon University Hospital, National and \\ Kapodistrian University of Athens Medical School, Athens, Greece
}

Clopidogrel and prasugrel are oral thienopyridine prodrugs that require cytochrome $\mathrm{P} 450$ (CYP)-mediated conversion to active metabolites that antagonize irreversibly the purinergic platelet $\mathrm{P} 2 \mathrm{Y} 12$ receptor $(\mathrm{R})$ leading to inhibition of adenosine diphosphate-mediated platelet activation and aggregation [1]. Since thienopyridines are metabolized by liver enzymes, there is a potential link between CYP2C19 genetic polymorphism (GP) and a high-on treatment platelet reactivity in certain carriers. CYP2C19 GPs, most importantly the *2 loss-of-function allele, have been associated with alterations in the pharmacodynamics (PD) and pharmacokinetics of clopidogrel, but not prasugrel, in patients undergoing percutaneous coronary interventions (PCI) [2-6].

The reduced susceptibility of prasugrel PD to genetic variants is possibly related to the different metabolization steps required: one esterase-mediated hydrolysis step and one CYP-mediated oxidation step for prasugrel activation process, instead of 2 CYP-mediated oxidation steps required for clopidogrel. In fact, prasugrel following its rapid absorption, is hydrolysed by esterases, such as those located in the intestine and blood, to a thiolactone intermediate metabolite R-95913. This metabolite undergoes subsequent activation by a single CYP-dependent step (predominantly CYP3A, CYP2B6 and to a lesser extent by CYP2C9 and

\section{KARGER}

() 2018 S. Karger AG, Basel

E-Mail karger@karger.com

www.karger.com/crd
CYP2C19) to form the sulfhydryl-containing active metabolite R-138727. This active metabolite binds irreversibly to the platelet P2Y12R by covalent linkage of a sulfhydryl group to inhibit platelet activation and aggregation. The active prasugrel metabolite contains a reactive thiol group, which forms a disulphide bridge with a free cysteine residue on the P2RY12R. Once irreversibly bound to prasugrel, the receptor is unable to bind adenosine diphosphate, and platelet activation via this pathway is prevented for the rest of the platelet's lifespan of about 10 days $[7,8]$.

In the Trial to Assess Improvement in Therapeutic Outcomes by Optimizing Platelet Inhibition with Prasugrel (TRITON)-TIMI 38 study, a significantly reduced rate of the composite efficacy endpoint of cardiovascular death, myocardial infarction, or stroke was demonstrated in prasugrel-treated patients compared to clopidogreltreated patients with acute coronary syndromes undergoing PCI [9]. However, there was an increased risk for major bleeding in very elderly (VE; $\geq 75$ years) and low body weight (LBW; $<60 \mathrm{~kg}$ ) patients receiving the prasugrel 10 $\mathrm{mg}$ maintenance dose (MD). A lower prasugrel dose 5-mg was suggested in these patients to reduce the bleeding risk based on a TRITON-TIMI 38 sub-study [10].

The influence of CYP2C19 genotype on pharmacokinetics and $\mathrm{PD}$ response during prasugrel 5-mg $\mathrm{MD}$ in 
LBW or VE patients undergoing PCI is not very well established. In addition, most studies utilized an early assessment of PR evaluated before or just after drug loading, while the maintenance phase data are scarce. Therefore, whether prasugrel response is consistent, or variable in outpatients, and whether the link of GP with PR differ over time needs to be explored further, among both approved prasugrel MDs.

In the last issue of Cardiology, Li et al. [11] prospectively studied 206 consecutive patients who underwent PCI in their centre. All patients were of Korean origin and received prasugrel loading dose of $60-\mathrm{mg}$ at least $3 \mathrm{~h}$ before PCI. Dual antiplatelet therapy (DAPT) was later maintained with $100-\mathrm{mg} /$ day of aspirin, and $10-\mathrm{mg} /$ day $(n=76)$ or $5-\mathrm{mg} /$ day $(n=130)$ of prasugrel in LBW and/or VE patients. Blood samples for platelet aggregation and genetic tests were obtained simultaneously from patients after 1 month following PCI with most sampling occurred between 30 and 90 days, with a mean of 64.7 days after PCI. The residual platelet aggregation (RPA) was measured by 3 different methods for platelet activity assessment (light transmittance aggregometry [LTA], multiplate electrode aggregometry, and VerifyNow [PRU]). RPA was lower after 10-mg prasugrel dose, when compared to 5-mg prasugrel daily, and there was a consistent trend toward higher aggregation in CYP2C19 carriers independently from maintenance dosing, reaching significance for 10 - mg pra- sugrel. CYP2C19 carriers had higher RPA for 5- $\mathrm{mg}(n=35$; LTA: $p=0.043$, multiplate electrode aggregometry: $p=$ $0.023)$, and reached significance for $10-\mathrm{mg}(n=27$; LTA: $p=0.001$, PRU: $p=0.001$ ) prasugrel. The authors concluded that CYP2C19 GP impacts RPA during the maintenance prasugrel phase in Korean outpatients. This effect is consistent for both approved prasugrel MDs potentially affecting long-term outcomes including bleeding risks [11].

The most important message from the current study is the fact that CYP2C19 genotype carriers may still have some impact on residual post-prasugrel PR during the maintenance phase, while on DAPT in Korean outpatients. Since almost all work on prasugrel response genetics were done early post-PCI [12], or around the loading phase, the index evidence yielded from East Asian patients on long-term maintenance response is indeed new. Importantly, the link between GPs and drug-related responses are especially valid in Asians since about $50 \%$ of Asian population comprises loss-of-function allele carriers. In contrast to the negative findings at the acute inhospital setting, and of another study which found no significant difference in $\mathrm{PD}$ response for prasugrel 5 or 10 $\mathrm{mg}$ in stable CAD patients [13] and disagrees with the index data, it seems that there could be a delayed impact of GP on PR in this population of patients. Further studies with a larger number of patients are required involving populations other than the East Asians.

\section{References}

1 Jakubowski JA, Winters KJ, Naganuma $\mathrm{H}$, Wallentin L: Prasugrel: a novel thienopyridine antiplatelet agent: a review of preclinical and clinical studies and the mechanistic basis for its distinct antiplatelet profile. Cardiovasc Drug Rev 2007;25:357-374.

2 Kassimis G, Davlouros P, Xanthopoulou I, Stavrou EF, Athanassiadou A, Alexopoulos D: CYP2C19*2 and other genetic variants affecting platelet response to clopidogrel in patients undergoing percutaneous coronary intervention. Thromb Res 2012;129:441446.

3 Alexopoulos D, Dimitropoulos G, Davlouros $\mathrm{P}$, et al: Prasugrel overcomes high on-clopidogrel platelet reactivity post-stenting more effectively than high-dose (150-mg) clopidogrel: the importance of CYP2C19*2 genotyping. JACC Cardiovasc Interv 2011;4:403-410.

4 Mega JL, Close SL, Wiviott SD, Shen L, Hockett RD, Brandt JT, et al: Cytochrome P450 genetic polymorphisms and the response to prasugrel: relationship to pharmacokinetic, pharmacodynamic, and clinical outcomes. Circulation 2009;119:2553-2560.
5 Varenhorst C, James S, Erlinge D, Brandt JT, Braun OO, Man M, et al: Genetic variation of CYP2C19 affects both pharmacokinetic and pharmacodynamic responses to clopidogrel but not prasugrel in aspirin-treated patients with coronary artery disease. Eur Heart J 2009;30:1744-1752.

6 Kassimis G, Stavrou EF, Alexopoulos D, Athanassiadou A: Cytochrome P450 2C19 polymorphism and antiplatelet therapy. Who should really be genotyped? Curr Pharm Des 2013;19:2489-2495.

7 Kurihara A, Hagihara K, Kazui M, Ishizuka T, Farid NA, Ikeda T: In vitro metabolism of antiplatelet agent clopidogrel: cytochromeP450 isoforms responsible for two oxidation steps involved in the active metabolite formation. Drug Metab Rev 2005;37:99.

8 Rehmel JL, Eckstein JA, Farid NA, et al: Interactions of two major metabolites of prasugrel, a thienopyridine antiplatelet agent, with the cytochromes P450. Drug Metab Dispos 2006; 34:600-607.

9 Wiviott SD, Braunwald E, McCabe $\mathrm{CH}$, Montalescot G, Ruzyllo W, Gottlieb S, et al: Prasu- grel versus clopidogrel in patients with acute coronary syndromes. N Engl J Med 2007;35: 2001-2015.

10 Riesmeyer JS, Salazar DE, Weerakkody GJ, Ni L, Wrishko RE, Ernest CS, et al: Relationship between exposure to prasugrel active metabolite and clinical outcomes in the TRITONTIMI 38 substudy. J Clin Pharmacol 2012;52: 789-797.

11 Li JX, Kima MH, Guoa LZ, et al: Impact of CYP2C19 polymorphism on antiplatelet potency of prasugrel 5 and $10 \mathrm{mg}$ daily maintenance. Cardiology 2018;140:155-162.

12 Xanthopoulou I, Stavrou EF, Kassimis G, Goudas P, Alexopoulos D: Resistance to highmaintenance dose of prasugrel treated by ticagrelor: a case report. Platelets 2013;24:239241.

13 Gurbel PA, Bergmeijer TO, Tantry US, et al: The effect of CYP2C19 gene polymorphisms on the pharmacokinetics and pharmacodynamics of prasugrel 5-mg, prasugrel $10-\mathrm{mg}$ and clopidogrel 75-mg in patients with coronary artery disease. Thromb Haemost 2014; 112:589-597. 